\title{
UPAYA MEMINIMALISIR DAMPAK LINGKUNGAN DARI PENGGUNAAN PESTISIDA DALAM PERTANIAN (DAMPAK LTNGKUNGAN DAN PENANGGULANGANNYA)
}

\author{
Hadis Jayanti dan Dewa Ngurah Suprapta \\ Jurusan Hama dan Penyakit Tumbuhan \\ Fakultas Pertanian, Universitas Udayana \\ adisc-hehe@yahoo.com
}

\section{SUMMARY}

\section{Minimizing the Environmental Risk of the use of Pesticide in Agriculture (Environmental Impact and} Mitigation)

Utilization of synthetic pesticide seems up to now remains to be one of the methods in controlling pest and plant disease because it plays a role in determining the quality and quantity of the crops. Improver of synthetic pesticide in agriculture can adversely affect the ecosystem such as water and soil pollution. The occurrence of pest resistance, the outbreak of secondary pest, resurgence of pest, the death of predators, residue of pesticide in food, and the pesticide residue that affects man's health.

Although it has been widely known that pesticide has bad impact to the environment, the use of pesticide is still needed in agricultural practice. Its use needs to pay attention to the concept of Integrated Pest Management in which the use of pesticide is only made when it is absolutely necessary, that is, when the population of pest increases and lies above one level of pest population, the Economic Treshold (Untung, 1993). To know the safety level of pesticide, an evaluation of toxicity of pesticide is needed and it is commonly tested in animal of high level. This is done in such away that the toxicity and safety level of the pesticide can be known by farmers, users of pesticide, and the environment. Based on the information of the toxicity level, it is expected that the steps of environmental management can be taken to minimize the negative impact of pesticide.

The effort of minimizing the negative impact of pesticide can be done in a variety of ways. For example direction given to the users in terms of giving the dosage, application time, safe working procedure, choosing pesticide with precise target, choosing pesticide that can decompose easily, application target, time before harvest, tool and exact application technique, keeping as small pollution as possible. In the future it is hoped that the use of pesticide will decrease and will be more selective, and supported by new inventions in the technology of processing pesticide disposal and the technology of utilizing botanical pesticide which are all expected to be effective in overcoming the disturbance of pest and plant disease at the same time minimizing environmental degradation.

Keywords: pesticide, negative impact, agriculture environment

\section{PENDAHULUAN}

Organisme Pengganggu Tanaman (OPT) merupakan salah satu faktor pembatas dalam meningkatkan produksi tanaman. Total kehilangan hasil akibat OPT diperkirakan sekitar $50 \%$ (Suprapta, 2003). Berbagai usaha dilakukan untuk mengendalikannya, salah satunya adalah dengan pestisida sintetis. Pemakaian pestisida sintetis di Indonesia cukup tinggi, pada awal 1990-an penggunaannya teiah mencapai 20.000 ton. Jumlah ini ditengarai masih tinggi di era reformasi mengingat pada tahun 2000 pestisida sintetik yang terdaftar di Komisi Pestisida mencapai 594 merek dagang (Suprapta, 2005). Tingginya pemakaian pestisida karena menurut pengalaman petani pestisida sintetis sangat mem bantu dalam mempertahankan hasil pertaniannya dan memberikan respon yang relatif cepat (Suprapta, 2003).
Penggunaan pestisida sintetis yang tidak benar dalam pertanian bisa berdampak buruk terhadap ekosistem. Akumulasi senyawa kimia pestisida sintetis di alam yang sulit terurai berdampak pada lingkungan sekitarnya:, 1) matinya agensia-agensia hayati menguntungkan, 2) kepunahan jenis organisme tertentu,3) terjadinya kelainan-kelainan genetis organisme, dan sebagainya. Akibat pemakaian pestisida sintetis, pada tahun 1984 ada sekitar 447 jenis serangga dan tungau, 100 jenis patogen tanaman, 55 jenis gulma, 2 jenis nematoda parasit, dan 5 jenis binatang pengerat kebal pestisida (Suprapta, 2005).

Walaupun telah diketahui pestisida memiliki dampak buruk terhadap lingkungan. namun penggunaan pestisida masih tetap diperlukan dalam pertanian. Penggunaan pestisida dalam pertanian perm memperhatikan konsep Pengendalian Hama Terpadu, yaitu 
penggunaan pestisida hanya dilakukan apabila benar - benar perlu pada saat populasi hama meningkat dan berada di atas suatu aras populasi hama yaitu Ambang Ekonomi (AE) (Untung, 1993). Karena tidak bisa dipisahkan dari pertanian, maka diperlukan suatu cara untuk meminimalisir dampak negatif dari pestisida pada lingkungan.

\section{ULASAN}

\section{Pengaruh Negatif Pestisida}

Pestisida jika diartikan secara istilah memiliki dua penggalan kata yaitu pest yang artinyahama dan sidayang artinya pembunuhjadi secara harfiah pestisida berarti zat kimiayang dapat membunuh hama. Pestisida adalah racun yang didefinisikan sebagai senyawa kimia yang digunakan untuk mencegah, merusak, mengusir atau mengurangi hama (Suprapta, 2005). Pestisida mungkin merupakan bahan kimiawi yang dalam sejarah umat manusia telah memberikan banyak jasanya baik dalam bidang pertanian, kesehatan, pemukiman, dan kepentingan masyarakat lainnya (Untung, 1993).

Di samping segala keberhasilannya manusia semakin merasakan dampak negatif pestisida. Beberapa pengaruh negatif pestisida antara lain : (1) Pencemaran air dan tanah. Contoh kasus pencemaran lingkungan karena pestisida di Indonesia adalah pada Juli 2007 diketahui bahwa sungai Kapuas di Kalimantan Barat tercemar "merkuri" dari industri penambangan emas di sungai tersebut.
Pencemaran tersebut diprediksi akan berpengaruh terhadap manusia dan mahluk lainnya karena mengkonsumsi air yang berasal dari sumber pencemaran tersebut (Anonim, 2007); (2) Mempengaruhi ekosistem pertanian, diantaranya menyebabkan kekebalan atau resistensi berbagai jenis hama, mempengaruhi keanekaragaman hayati pada ekosistem pertanian; (3) Matinya musuh aiami dari hama maupun patogen, menimbulkan resurgensi, yaitu serangan hama yang jauh lebih berat dari sebelumnya. Kematian serangga berguna seperti lebah yang sangat berguna untuk penyerbukan. Dan terjadinya serangan hama sekunder. Contohnya : penyemprotan insektisida sintetis secara rutin untuk mengendalikan ulat grayak (hama primer) dapat membunuh serangga tain seperti walang sembah yang merupakan predator kutu daun (hama daun). Akibatnya setelah ulat grayak dapat dikendalikan kemungkinan besar tanaman akan diserang kutu daun; (4) Adanya residu pestisida pada bahan makanan yang dikonsumsi akan dapat mempengaruhi kesehatan manusia. Badan Pengawas Pestisida, Komite Residu Pestisida (KRP), telah menguji 85 sampei jenis pangan organik. Ternyata semua tidak mengandung residu pestisida. Pada saat yang sama, telah diuji 957 sampei pangan non organik yang memperlihatkan hasil sebanyak 203 jenis (21 persen) mengandung pestisida. Komite Residu Pestisida teiah mempublikasikan hasil analisa pestisida selama 9 bulan (tiga per empat bagian) di tahun 2005. Berikut hasil uji residu pestisida pangan organik dan non organik.

Tabel 1. Hasil uji residu pestisida pangan organik dan non organik

\begin{tabular}{lcccc}
\hline \multicolumn{1}{c}{ Produk } & Sampei & Sampei Organik & $\begin{array}{c}\text { Sampei Organik } \\
\text { dgn Residu (\%) }\end{array}$ & $\begin{array}{c}\text { Sampe! Non Organik } \\
\text { dgn Residu (\%) }\end{array}$ \\
\hline Kacang hijau & 27 & 0 & 0 & 10 \\
Roti & 72 & 1 & 0 & 63 \\
Roti Beraroma & 33 & 0 & 0 & 22 \\
Bawang Merah & 24 & 2 & 0 & 14 \\
Mentega & 72 & 2 & 0 & 15 \\
Makanan Sereal & 72 & 13 & 0 & 9 \\
Telur & 60 & 3 & 0 & 0 \\
Bawang Putih & 24 & 0 & 0 & 0 \\
Makanan Bayi & 62 & 24 & 0 & 0 \\
Susu & 78 & 22 & 0 & 5 \\
Jamur & 48 & 2 & 0 & 8 \\
Minyak Sayur & 72 & 2 & 0 & 7 \\
Beras & 72 & 11 & 0 & 0 \\
\hline
\end{tabular}

Sumber: Widiastuti, 2006.

Mengevaluasi Toksisitas Pestisida pada Hewan Tingkat Tinggi
Agar dapat mengetahui toksisitas pestisida tertentu, dapat dilakukan evaluasi toksisitas pestisida pada hewan tingkat tinggi, hal ini untuk mengetahui segi keamanan pestisida terhadap 
petani dan pemakai pestisida. Proses untuk menentukan LD50 adalah sama, dan penekanannya itbih pada aspek kualitatif dari keracunan. Pemilihan hewan uji biasanya didasarkan atas tingkat kepraktisan dan biaya, biasanya digunakan tikus atau mencit. Hewan yang digunakan harus sehat dan mempunyai keseragaman genetik. Faktor yang mempengamhi toksisitas adalah ; lamanya exposure, spesies, variasi individu, umur, jenis kelamin, kerapatan, suhu, nutrisi, dan cara masuk pestisida. Toksisitas pestisida akibat pemberlakuan pada hewan percobaan dalam kondisi keracunan akut dan keracunan kronis (Suprapta, 2005).

\section{Keracunan Akut}

Keracunan akut didefinisikan sebagai keracunan yang menyebabkan kerusakan atau kematian akibat exposure tunggal atau berulangulang selama periode waktu singkat, biasanya 24 jam. Cara masuknya pestisida umumnya lewat mulut. Ada dua cara perlakukan lewat mulut. Metode pertama, menambahkan insektisida ke dalam makanan atau memasukkan langsung ke dalam perut tikus dengan alat khusus. Volume pestisida yang masuk tidak boleh melebihi dari $2-3 \%$ berat badan tikus. Metode lain untuk memperlakukan pestisida adalah injeksi. Dengan cara ini pestisida bisa masuk secara langsung ke dalam aliran darah. Volume untuk diinjeksikan tidak boleh lebih besar dari 0,1 - 0,5 $\mathrm{ml}$ per tikus (Suprapta, 2005).

Analisa keracunan pada manusia dilakukan dengan mengurai udara disekitarnya. Standarnya, volume pernafasan seorang laki-laki yang melakukan pekerjaan ringan diperkirakan $36 \mathrm{~m}^{1}$ / hari. Hartwell, et al. (1964) menemukan ratio toksisitas parathion terhadap manusia adalah $10: 3$ : I masing-masing lewat pernafasan, mulut, dan kulit. Toksisitas lewat pernafasan biasanya dinyatakan sebagai miligram bahan aktif per $\mathrm{m}^{\prime}$ ruang udara $\left(\mathrm{mg} / \mathrm{m}^{1}\right)$. Nilai ambang batas (TLVs = TresholdLimit Values) yaitu : konsentrasi pestisida terbawa udara \{airbone) dan menunjukkan kondisi dimana dipercayai hampir semua petani/pekerja waiaupun mungkin berulangulang terpapar pestisida, dari hari ke hari, tanpapengaruh negatif (Suprapta, 2005).

Selengkapnya nilai ambang batas pestisida dapat dilihat pada tabel 2. Apabila analisa kandungan pestisida dilakukan disuatu tempat maka daftar pestisida dan nilai TLVs nya dapat dijadikan sebagai acuan tingkat pencemaran udara di lingkungan tersebut.

Tabel 2. Nilai TLVs beberapa jenis pestisida dan senyawa lainnya.

\begin{tabular}{|c|c|c|c|}
\hline Jenis Senyawa & TLVs (mg/m3) & Jenis Senyawa & TLVs (mg/m3) \\
\hline Aldrin & 0,25 & Fonofos & 0,1 \\
\hline Amitrole & 0,2 & Heptachlor & 0,5 \\
\hline Arsenic and soluble comp. & 0,2 & Hexan & 176 \\
\hline Azinphos methyl & 0,2 & Hydrogen chiorida & 7,5 \\
\hline Benomyl & 10 & $\mathrm{HCN}$ & 11 \\
\hline Bromacil & 11 & PbArsenat & 0,15 \\
\hline Bromine & 0,66 & Lindane & 0,5 \\
\hline Camphor & 12 & Malathion & 10 \\
\hline Captafol & 0,1 & Methomyl & 2,5 \\
\hline Captan & 0,5 & Methoxychlor & 2,5 \\
\hline Carbaryl & 5,0 & Methyj^bromida & 19 \\
\hline Carbofiiran & 0,1 & Methyl demeton & 0,5 \\
\hline Carbon disulfide & 31 & Methyl isothiocyanate & 0,047 \\
\hline Carbon tetrachlorida & 31 & Methyl parathion & 0,2 \\
\hline Chlordane & 0,5 & Mevinphos & 0,09 \\
\hline Chloropicrin & 0,67 & Naled & 3,0 \\
\hline Chlopyrifos & 0,2 & Napthalene & 52 \\
\hline Cyanide & 5,0 & Nicotine & 0,5 \\
\hline Cyhexatin & 5,0 & Paraquat & 0,1 \\
\hline $2,4 \mathrm{D}$ & 10 & Parathion & 0,1 \\
\hline DDT & 1,0 & Pentachlorophenol & 0,5 \\
\hline Demeton & 0,11 & Phorate & 0,05 \\
\hline Diazinon & 0,1 & Phosphine & 0,42 \\
\hline 1,2dichloroethylene & 793 & Pichloram & 10 \\
\hline Dichlorovos & 0,90 & Pindone & 0,1 \\
\hline Dicrotophos & 0,25 & Pyrethrum & 5,0 \\
\hline Dinitri-o-cresol & 0,2 & Ronnel & 10 \\
\hline
\end{tabular}




\begin{tabular}{lllc}
\hline Diquat & 0,5 & Rotenone & 5,0 \\
Disulfoton & 0,1 & Sodium fluoroacetate & 0,05 \\
Diuron & 10 & Starch & 10 \\
Endosulfan & 0,1 & Sucrose & 10 \\
Endrin & 0,1 & Sulfotep & 0,2 \\
EPN & 0,5 & Sulfuric acid & 1,0 \\
Ethion & 0,4 & $2,4,5-T$ & 10 \\
Ethylene dibromidae & 2,0 & Temephos & 10 \\
Ethyl ether & $\mathbf{1 2 1 0}$ & TEPP & 0,047 \\
Fenamiphos & 0,1 & Thiram & 5,0 \\
Fensulfothion & 0,1 & Toxaphene & 0,5 \\
Ferbam & 10 & Warfarin & 0,1 \\
\hline
\end{tabular}

Sumber : Perry et a!., 1988 dalam Suprapta, 2005.

\section{KeracunanKronis}

Keracunan kronis adalah keracunan akibat pengaruh pestisida yang tidak segera tampak. Keracunan kronis terjadi karena pestisida yang digunakan dosisnya relatif rendah tetapi terpapar (exposure) secara berulang kali dalam kurun waktu lama. Pengujiannya dengan menggunakan hewan dalam waktu paparan selama 6-18 bulan. Hewan percobaan yang kecil seperti tikus dapat dilakukan seumur hidupnya. Berbagai gejala sakit atau penyimpangan fisiologis dan patologis diamati dan dicatat. Keracunan kronis bisa menyebabkan pengaruh sekunder pada tubuh hewan tersebut. Diantaranya, karsinogenisitas (menyebabkan kanker), mutagenisitas (menyebabkan mutasi), dan teratogenesitas atau kelainan yang disebabkan oleh perkembangan embryo yang tidak normal (Suprapta, 2005). Aspek penting lainnya menyangkut keracunan kronis adalah NOEL (no observed effect level) yang didefinisikan sebagai dosis maksimum atau mendekati maksimum, dimana tidak terjadi perbedaan antara perlakuan pestisida dan kontrol. Pada tabel 3. akan diberikan nilai ADI dan NOEL beberapajenis pestisida.

\begin{tabular}{|c|c|c|c|c|}
\hline Nama Umum & $\begin{array}{c}\text { ADI } \\
\wedge \wedge \mathrm{mg} / \mathrm{kg} \text { berat badan) }\end{array}$ & Hewan & $\begin{array}{c}\text { NOEL } \\
\mathrm{mg} / \mathrm{kg} \text { berat badan) }\end{array}$ & $\begin{array}{l}\text { Periode } \\
\text { paparan }\end{array}$ \\
\hline \multicolumn{5}{|l|}{ Organochlorines } \\
\hline \multirow[t]{3}{*}{ DDT } & \multirow[t]{3}{*}{0,02} & Tikus & 6,25 & \multirow{3}{*}{$\begin{array}{l}\text { Sepanjang hidup } \\
7 \text { tahun } \\
25 \text { tahun }\end{array}$} \\
\hline & & Monyet & 10 & \\
\hline & & Manusia & 0,25 & \\
\hline \multirow[t]{2}{*}{ Dieldrin } & \multirow[t]{2}{*}{0,0001} & Tikus & 0,025 & \multirow{2}{*}{$\begin{array}{l}2 \text { tahun } \\
68 \text { minggu }\end{array}$} \\
\hline & & Anjing & 0,025 & \\
\hline \multirow[t]{3}{*}{ Endosulfan } & \multirow[t]{3}{*}{0,006} & Tikus & 0,6 & 2 tahun \\
\hline & & Mencife & 0,84 & 2 tahun \\
\hline & & Anjing & 0,57 & 1 tahun \\
\hline \multirow[t]{2}{*}{ Lindane } & \multirow[t]{2}{*}{0,008} & Tikus & 0,75 & 13 minggu \\
\hline & & Anjing & 1,6 & 2 tahun \\
\hline \multicolumn{5}{|c|}{ Organophosphorus } \\
\hline \multirow[t]{4}{*}{ Azinphos methyl } & \multirow[t]{4}{*}{0,005} & Tikus & 0,86 & \multirow{4}{*}{$\begin{array}{l}2 \text { tahun } \\
2 \text { tahun } \\
52 \text { minggu } \\
30 \text { had }\end{array}$} \\
\hline & & Mencit & $\mathbf{0 , 8 8}$ & \\
\hline & & Anjing & 0,74 & \\
\hline & & Manusia & 0,3 & \\
\hline \multirow[t]{4}{*}{ Diazinon } & \multirow[t]{4}{*}{0,002} & Tikus & 0,07 & 99 minggu \\
\hline & & Anjing & 0,02 & 1 tahun \\
\hline & & Kelinci & 25 & Periode embryo \\
\hline & & Manusia & 0,025 & $34-36$ hari \\
\hline \multirow[t]{3}{*}{ Fenitrothion } & \multirow[t]{3}{*}{0,005} & Tikus & 0,5 & \multirow[t]{3}{*}{ Periode embryo } \\
\hline & & Anjing & 1,25 & \\
\hline & & Manusia & $\mathbf{0 , 0 8}$ & \\
\hline
\end{tabular}




\begin{tabular}{lllll}
\hline Malathion & 0,02 & Tikus & 5 & 2 tahun \\
& & Manusia & $\mathbf{0 , 2}$ & 47 atau 88 hari \\
Parathion & 0,004 & $\begin{array}{l}\text { Manusia } \\
\text { Tikus }\end{array}$ & 0,05 & 3 minggu \\
Carbamate & & 0,25 & 2 tahun \\
Carbaryl & 0,003 & Tikus & $\mathbf{1 0}$ & 2 tahun \\
& & Anjing & $\mathbf{1 , 8}$ & I tahun \\
Carbofuran & 0,002 & Manusia & $\mathbf{0 , 0 0 6}$ & 6 minggu \\
& & Tikus & $\mathbf{1}$ & 2 tahun \\
Methomyl & 0,03 & Mencit & 2,8 & 2 tahun \\
& & Tikus & 2,5 & 9 hari \\
& & Anjing & 3,1 & 2 tahun \\
\hline
\end{tabular}

Sumber : Sekizawa, 1997 dalam Suprapta 2005.

\section{Upaya Meminimalisir Pengaruh Negatif Pestisida}

Pestisida merupakan bahan berbahaya yang dapat menimbulkan pengaruh negatif terhadap kesehatan manusia dan kelestarian lingkungan hidup. Dampak negatif yang timbul diusahakan sekecil mungkin, sedangkan manfaatnya diupayakan sebesar mungkin, dalam hal ini memperkecil residu pestisida pada hasil pertanian, dapat ditempuh langkah-langkahsebagai berikut:

\section{Pemilihan Jenis Pestisida}

a. Memilih Pestisida yang Mudah Terurai (TidakPersisten).

Suatu pestisida tertentu mempunyai si fat mudah teroksidasi, tereduksi, terhidrolisa dan mengalami reaksi lain sehingga akan rusak atau bahkan menjadi senyawa Iain yang tidak berbahaya. Berdasarkan sifat fisikokimianya ada pestisida yang tidak mudah rusak di alam, sehingga tetap berada di alam dalam jangka waktu panjang (persisten). Sebaliknya, ada pestisida yang mudah rusak/berubah menjadi senyawa lain di alam sehingga keberadaannya di alam hanya dalam waktu pendek (non persisten). Untuk mengukur mudah tidaknya suatu pestisida rusak/terurai di alam, digunakan parameter waktu paruh \{Decomposition Time-50 disingkat DT-50) atau senyawa tersebut terurai di alam (dalam hal ini, unsur alam yang sering digunakan adalah tanah, air, udara). DT-50 pestisida sangat beragam, dari jangka waktu jam sampai dengan jangka waktu tahun (Sofia, 2001). Pada tabel 4. berikut adalah jumlah dan jenis pestisida yang beredar di Bali selama 5 tahun terakhir.

Tabel 4. Jumlah (kg/It) dan Jenis pestisida yang beredar di Bali selama 5 tahun.

\begin{tabular}{rlccrrc}
\hline \multirow{2}{*}{ No. } & \multirow{2}{*}{ Jenis } & \multicolumn{5}{c}{ Tahun } \\
\cline { 3 - 6 } i. & Insektisida & 2002 & 2003 & 2004 & 2005 & 2006 \\
2. & Fungisida & $4.524,59$ & $18.629,38$ & $9.299,86$ & $24.895,40$ & $19.267,26$ \\
3. & Bakterisida & 93,05 & $3.810,17^{\prime \prime \prime}$ & 651,08 & $4.110,68$ & $4.096,00$ \\
4. & Herbisida & $2.280,00$ & $1.488,74$ & $1.507,17$ & $2.351,85$ & $1.933,36$ \\
5. & Rodentisida & 227,22 & 28,68 & 9,24 & 33,40 & 30,68 \\
6. & ZPT & 442,50 & 191,50 & 11,87 & 166,88 & 211,43 \\
7. & Bahan Perekat & 90,10 & - & - & 0,50 & - \\
& Jumlah & $30.083,56$ & $25.152,42$ & $11.497,06$ & $31.568,2 !$ & $25.538,73$
\end{tabular}

Sumber : BPTPH Bali, 2007.

b. Memilih Pestisida yang tepat sasaran.

Agar penggunaannya efektif, jenis pestisida yang akan digunakan hams tepat, yaitu disesuaikan dengan OPT (hama, penyakit, dan gulma) sasaran yang menyerang tanaman. Menurut OPT sasaran yang akan dikendalikan, pestisida dapat dikelompokkan antara lain pada tabel 6. 
Tabel 6. Pengelompokan pestisida berdasarkan fungsinya.

\begin{tabular}{llll}
\hline Kelompok Pestisida & \multicolumn{1}{c}{ Fungsi } & Kelompok Pestisida & \multicolumn{1}{c}{ Fungsi } \\
\hline Akarisida & Membunuh tungau & Insektisida & Membunuh serangga \\
Algisida & Membunuh alga & Moluskisida & Membunuh keong \\
Avicida & Membunuh burung & Nematisida & Membunuh nematoda \\
Bakterisida & Membunuh bakteri & Ovisida & Membunuh telur \\
Fungisida & Membunuh jamur & Pissisida & Membunuh ikan \\
Herbisida & Membunuh gulma & Rodentisida & Membunuh tikus \\
\hline
\end{tabular}

Sumber : Perry eta/., 1998 dalam Suprapta, 2005.

Tiap kelompok pestisida tersebut pada umumnya mempunyai sifat tersendiri dan tidak efektif terhadap OPT dari golongan yang lain, misalnya insektisida tidak dapat mengendalikan jendawan atau gulma. Tetapi ada juga satu jenis pestisida yang digolongkan ke dalam lebih dari satu kelompok, misalnya disamping sebagai insektisida juga sebagai nematisida, pissisida, dan sebagainya. Oleh karena itu, jenis pestisida yang dipiiih harus sesuai dengan OPT-nya. Kesalahan dalam memilih jenis pestisida berakibat tidak efektifnya pestisida tersebut, misalnya OPT tidak terkendali dan tanaman tidak "sembuh". Hal tersebut mendorong pengulangan aplikasi pestisida berkali-kali dalam jangka waktu pendek yang salah satu dampaknya adalah bertambahnya residu. Sebaliknya, apabila jenis yang dipiiih benar dan efektif maka tidak diperlukan aplikasi ulangan lagi sehingga residunya rendah. Oleh karena itu, OPT yang menyerang hams diamati secara cermat sebelum memilihjenis pestisida yang tepat (Sofia, 2001).

\section{Pengaturan Cara Aplikasi Pestisida}

1. Waktu Aplikasi

Aplikasi pestisida seharusnya hanya dilakukan pada waktu popuiasi atau intensitas serangan OPT telah melampaui ambang ekonomi atau ambang pengendalian. Jangan mengaplikasikan pestisida pada saat popuiasi atau intensitas serangan OPT masih di bawah ambang ekonomi, atau secara reguler tanpa memperhatikan populasi/intensitas serangan OPT, apalagi tidak ada serangan OPT. Hal ini dimaksudkan agar aplikasi pestisida hanya pada waktu yang diperlukan dan tidak berlebihan (Sofia, 2001).

\section{DosisAplikasi}

Dosis (liter atau kilogram pestisida per hektar tanaman) dan konsentrasi (mililiter atau gram pestisida per liter cairan semprot) yang digunakan adalah dosis dan konsentrasi minimum yang efektif terhadap OPT sasaran. Hal ini dimaksudkan agar penggunaan pestisida tidak berlebihan dan residunya tidak tinggi. (Sofia, 2001).

\section{SasaranAplikasi}

Perlu diupayakan semaksima! mungkin agar aplikasi pestisida diarahkan pada sasarannya yang tepat dimana pestisida tidak diaplikasikan pada bagian tanaman yang akan dikonsumsi, Apabila yang akan dikonsumsi adalah buahnya, maka aplikasi pestisida tidak diarahkan pada buah., serta aplikasikan pestisida pada bagian tanaman yang terserang atau ada popuiasi OPT-nya. Hal ini dimaksudkan agar pestisida terfokus pada bagian tanaman yang memerlukannya; sehingga efektif, efisien, dan tidak meninggalkan residu pada bagian tanaman yang tidak perlu diaplikasi. (Sofia, 2001).

4. Jangka Waktu Sebelum Panen

Aplikasi pestisida yang terakhir diusahakan sejauh mungkin sebelum panen. Makin jauh dari waktu panen makin baik. Hal ini dimaksudkan agar pada waktu hasil tanaman dipanen, sebagian besar pestisida sudah terurai, sehingga residunya hanya sedikit atau tidak ada. (Sofia, 2001).

5. Alat dan Teknik Aplikasi yang Tepat

Alat aplikasi antara lain penyemprot/sprayer (hand sprayer, power sprayer, mist blower), penghembus/duster, dan pengabut-panas/fogger mempunyai kinerja dan spesifikasi tertentu sesuai dengan tujuan penggunaan yang dirancang oleh pembuatnya. Penerapan teknik aplikasi yang tepat memungkinkan berfungsinya aiat tersebut secara 'optimal. Informasi tentang hal tersebut biasanya tercantum pada leaflet/brosur masing-masing. Penggunaan alat dan teknik aplikasi yang tepat lebih menjamin efektivitas dan efisiensi. Apabila aplikasinya efektif, maka OPT terkendali. Untuk memperkecil residunya, aplikasi pestisida tidak perlu diulang-ulang dalam jangka waktu pendek (Sofia, 2001).

\section{Peraturan dan Pengarahan Kepada Para Pengguna}

Pengarahan dapat dilakukan dengan pelatihan dan pengarahan kepada para pengguna pestisida. Dengan penggunaan pestisida yang bijaksana akan menghasilkan perbaikan dalam produksi dan kualitas pertanian tanpa 
meninggalkan dampak negatif pada lingkungan. Pengarahan ini dapat diadakan oleh organisasi industri-industri bahan-bahan kimia pertanian atau instansi pemerintah terkait (Ton, 1991 daiam Sofia, 2001).

Untuk melindungi keselamatan manusia, sumber kekayaan alam, dan agar pestisida dapat digunakan efektif, maka peredaran, penyimpanan dan penggunaan pestisida diatur dengan Peraturan Pemerintah No. 7 Tahun 1973 (Sudarmo, 1991 dalam Sofia, 2001). Standar keamanan untuk pengaplikasian pestisida dan pengarahan untuk penggunaan yang aman dari pestisida, seperti cara pelarutan, jumlah (konsentrasi), frekuensi dan periode dari aplikasi, ditentukan oieh aturan untuk meyakinkan bahwa tingkat residu tidak melebihi dari standar yang telah ditetapkan. Setiap kemasan dari bahanbahan kimia pertanian hams dilengkapi/ menggunakan keterangan perlindungan bagi keamanan pengguna. Penyimpanan yang tepat dari bahan-bahan kimia pertanian dan keterangan mengenai pelepasan dari bahan kimia pertanian ke lingkungan termasuk tingkat yang dapat meracuni dan digambarkan pada label dari kemasan tersebut. Berdasarkan keputusan menteri pertanian No. 434 tahun 2001 telah ditetapkan 37 jenis bahan aktif yang telah dilarang beredar (tabel 7).

Tabel 7. Bahan aktif pestisida yang dilarang beredar.

\begin{tabular}{|c|c|c|c|c|c|}
\hline No. & Bahan Aktif & No. & Bahan Aktif & No. & Bahan Aktif \\
\hline $\mathrm{I}$, & $2,3,5-\mathrm{T}$ & 13. & Dinoseb & 25. & Lindan \\
\hline 2. & 2,4,5-Triklorofenol & 14. & EPN & 26. & Metoksiklor \\
\hline 3. & 2,4,6 - Triklorofenol & 15. & Endrin & 27. & Mevinfos \\
\hline 4. & $\begin{array}{l}\text { Natrium } 4 \text { - Brorn-, } \\
\text { 5-diklorofenol }\end{array}$ & 16 & $\begin{array}{l}\text { Etilen Dibromedal } \\
\text { (EDB) }\end{array}$ & $\begin{array}{l}28 . \\
29 .\end{array}$ & $\begin{array}{l}\text { Monosodium metam } \\
\text { Natrium Klorat }\end{array}$ \\
\hline 5. & Aldikarb & 17. & Forfor merah & 30. & Natrium \\
\hline 6. & Aldrin & 18. & Halogen Fenol & & tribromofenol \\
\hline 7. & Arsonat(MSMA) & 19. & Heksaklorida(HCH) & 31. & Paration metil \\
\hline 8. & Cyhexatin & & dan isomerinya & 32. & Pentaklorofenol (PCP) \\
\hline \multirow[t]{2}{*}{9.} & Diklorodifeniltrikloroetan & 20. & Heptaklor & & dan garamnya \\
\hline & (DDT) & 21. & Kaptaklor & 33. & Senyawa arsen \\
\hline 10. & Dibromokloropropan (DBCP) & 22. & Klordan & 34. & Senyawa merkuri \\
\hline & Dieldrin & 23. & Kfordimefon & 35. & Striknin \\
\hline \multirow[t]{2}{*}{12.} & Diklorofenol & 24. & Leptofos & 36. & Telodrin \\
\hline & & & & 37. & Toxaphene \\
\hline
\end{tabular}

Sumber: BPTPH Bali, 2007.

\section{Penelitian yang Mendukung Kepada Usaha Pelestarian Lingkungan}

Kebijakan global pembatasan penggunaan pestisida sintetik, dapat menjadi kendala di dalam meningkatkan eksport komoditi pertanian, disamping juga semakin ketatnya peraturan mengenai keamanan lingkungan serta banyaknya kelemahan dalam pemakaian bahan kimia dan antibiotika untuk proteksi pertanian (Suwanto, 1994; Suwahyono, 1996 dalam Sofia, 2001).

Diperlukanteknologi untuk menghasiikan pestisida yang ramah lingkungan dan efektif mengendaiikan hama dan patogen tanaman, yaitu pemanfaatan pestisida nabati yang berasa! dari tumbuhan. Hal ini terjadi karena tumbuhan tingkat tinggi dapat menghasiikan senyawa kimia sebagai produk dari metabolisme sekunder yang mudah terurai di alam, sehingga meminimalisir dampak negatif pada lingkungan. Penelitian menunjukkan bahwa beberapa jenis pestisida nabati mampu mengendaiikan hama dan penyakit pada tanaman (Suprapta, 2003). Hasil penelitian menunjukkan bahwa minyak selasih (Ocimum (eniiifiontm) pada beberapa konsentrasi (20\%$100 \%$ ) secara signiflkan mampu mempengaruhi populasi lalat buah (Batrocera dorsalis) (Sumiartha et al 2005) Selain untuk mengendaiikan hama, pemanfaatan pestisida nabati juga dilaporkan berhasil untuk mengendaiikan patogen tanaman. Hasil penelitian menunjukkan penggunaan ekstrak daun sirih yang dikombinasikan dengan lengkuas merah efektif mengendaiikan penyakit layu fusarium pada pisang yang disebabkan oleh Fusarium oxysporum (Suprapta et at 2005).

Dengan adanya indikasi keberhasilan penelitian pestisida nabati untuk mengendaiikan hama dan penyakit tanaman, diharapkan produk pestisida masa depan menjadi ramah lingkungan 
karena memiliki daya mobilitas di tanah yang rendah, aktivitas unit yang tinggi, jangka waktu yang pendek, tidak menguap, mudah didekomposisi oleh mikroorganisme tanah, tingkat keracunan yang rendah pada hewan, perairan dan kehidupan di sekitarnya dan tingkat kerusakan produk yang rendah yang tidak membahayakan lingkungan (Ton, 1991;Uehara, 1993 dalam Sofia, 2001).

\section{SIMPULAN}

Pestisida adalah bahan-bahan kimia yang tidak terlepas penggunaannya untuk mengendalikan hama dan jasad pengganggu lainnya pada pertanian. Pestisida tidak saja membawa dampak yang positif terhadap peningkatan produk pertanian, tapi juga membawa dampak negatif terhadap lingkungan di sekitarnya. Upaya untuk meminimilisir dampak negatif pestisida dapat ditempuh dengan berbagai cara, yaitu: pengarahan kepada para pengguna dalam hal pemberian dosis, waktu aplikasi, cara kerja yang aman,memilih pestisida yang tepat sasaran, memilih pestisida yang mudah terurai, sasaran aplikasi, jangka waktu sebelum panen, serta alat dan teknik apiikasi yang tepat akan mengurangi sekecil mungkin pencemaran yang terjadi. Di masa yang akan datang diharapkan penggunaan pestisida akan berkurang dan lebih selektif dengan adanya peraturan mengenai standar keamanan pengaplikasian pestisida dan didukung oleh adanya penemuan-penemuan baruyang lebih efektif dalam mengatasi gangguan dari OPT.

\section{DAFTAR PUSTAKA}

Anonim, 2007. "Kasus Pencemaran Air" http://id.wikipedia.org/wiki/KasusPencemaranAir . Disidir tanggal 6 Juli 2007

Laba, W. 2001. "Keanekaragaman Hayati Artropoda Pada Ekosistem Padi $\mathrm{S}$ a w a $\mathrm{h}$ " http://tumoutou.net/3_seml_012/i_w_1 aba.htm. Disidirtanggal 6 Juli 2007.

Sofia, D. 2001. "Pengaruh Pestisida Dalam Lingkungan Pertanian". http://library.usu.ac.id/download/fp/fpdiana.pdf. Disidirtanggal 6 Juli 2007.

Suprapta, D.N. 2003. "Pemanfaatan Tanaman Lokal sebagai Pestisida Nabati untuk Meningkatkan Kemandirian Petani", Pidato Pengukuhan Guru Besar Jurusan Hama dan Penyakit Tumbuhan, Fakuitas Pertanian, Universitas Udayana. hal 33.

Suprapta, D.N. 2005. " Pertanian Bali Dipuja Petaniku Merana". Taru Lestari Foundation. Jakarta.

Sutarga, M. 2007. " Pencegahan Efek Pestisida Pada Petani Di Desa Buahan Kintamani". Jurnal Penelitian Pengabdian Masyarakat. Udayana Mengabdi. Denpasar.

Untung, K. 1993. "Pengantar Pengelolaan Hama Terpadu". Gadjah Mada University Press. Yogyakarta.

Widiastuti, S. 2006. "Perbandingan Pestisida Pada Pangan OrganikDan Non Organik". 